\title{
PENERAPAN SENTIMENT ANALYSIS PADA HASIL EVALUASI DOSEN DENGAN METODE SUPPORT VECTOR MACHINE
}

\author{
Valonia Inge Santoso ${ }^{1}$, Gloria Virginia ${ }^{2}$, Yuan Lukito ${ }^{3}$ \\ Program Studi Teknik Informatika \\ Fakultas Teknologi Informasi \\ Universitas Kristen Duta Wacana \\ valoniainge@ti.ukdw.ac.id ${ }^{1}$, virginia@staff.ukdw.ac.id ${ }^{2}$, yuan@staff.ukdw.ac.id ${ }^{3}$
}

\begin{abstract}
The quality of lectures can be determined by some feedbacks from students. From the feedbacks, we can give appreciations for those lectures who get good feedback from students, and evaluations for those who get bad feedback. The problem is classifying large size of feedbacks manually isn't effective and took a lot of time. Therefore, we need a system that can classify feedbacks automatically. These feedbacks will be classified into positive, negative, and neutral, usually called as sentiment analysis. Sentiment analysis implementation can be done by several methods, one of them that has a good accuracy is Support Vector Machine (SVM). SVM performance in this research is measured with the level of accuracy. The number of accuracy indicate the success level of system. The conclusion of this research is factors that affects the accuracy. The factors are the range of each classes and number of unique words in the training document.
\end{abstract}

Keywords: sentiment analysis, support vector machine, inverse matrix

\section{PENDAHULUAN}

Universitas Kristen Duta Wacana menerapkan kuesioner online dalam rangka penilaian terhadap dosen. Kuesioner ini diisi oleh mahasiswa dan berisi opini positif, negatif, atau netral. Saat ini, untuk perekapan dan klasifikasi hasil kuesioner untuk evaluasi dosen ini dilakukan secara manual. Pengklasifikasian secara manual memang menghasilkan data yang akurat karena manusia dapat membedakan dengan tepat apakah kata atau kalimat tersebut bermakna positif, negatif, atau netral, namun hal ini tidak efektif dan tidak menutup kemungkinan adanya kalimat ambigu yang sulit diklasifikasi walaupun oleh manusia sekalipun. Selain itu, pengklasifikasian secara manual membutuhkan banyak waktu dan tenaga. Untuk mengatasi masalah ini, dibutuhkan sistem yang dapat mengklasifikasikan opini ini ke dalam kelas sentimen positif, negatif, atau netral secara otomatis. Klasifikasi ke tiga kelas sentimen ini disebut sentiment analysis.

Sistem ini menggunakan metode support vector machine (SVM) karena pada penelitian - penelitian sebelumnya yang pernah dilakukan, metode ini memiliki nilai akurasi yang cukup tinggi. Dengan diterapkannya metode SVM, sistem ini diharapkan dapat melakukan sentiment analysis dengan cepat, mudah, dan dengan tingkat akurasi serta efektivitas yang cukup tinggi.

\section{LANDASAN TEORI}

2.1 Text Mining dan Sentiment Analysis

Text mining mengacu pada proses mengambil informasi berkualitas tinggi dari teks. Informasi yang diambil biasanya mengacu ke beberapa kombinasi relevansi, kebaruan, dan interestingness (Saraswati, 2011).

Sentiment analysis atau yang biasa disebut dengan Opinion mining adalah riset komputasional dari opini, sentimen, dan emosi yang dituangkan secara tekstual lalu diklasifikasikan menjadi kelompok sentimen positif dan negatif (Feizar, Indrianti, \& Yudistira, 2014). Secara umum, sentiment analysis dibagi menjadi 2 kategori besar (Wicaksono, 2011), yaitu:

1. Coarse - grained sentiment analysis: Proses analisis dan klasifikasi orientasi sebuah dokumen secara keseluruhan. Orientasi ini dibagi menjadi 3 jenis yaitu positif, netral, dan negatif, akan tetapi ada juga yang menjadikan nilai orientasi bersifat kontinu / tidak diskrit.

2. Fined - grained sentiment analysis: Obyek yang diklasifikasi tidak pada level dokumen melainkan pada level kalimat dalam sebuah dokumen. Sebagai contoh:

a. Cara pengajaran kurang menarik $\rightarrow$ negatif

b. Kuliah terlaksana dengan tepat waktu $\rightarrow$ positif Sentiment analysis terdiri dari 3 subproses (Wicaksono, 2011) yaitu:

1. Subjectivity Classification: menentukan kalimat yang merupakan opini.

2. Orientation Detection: Pengklasifikasian opini ke dalam kelas positif, negatif, atau netral.

3. Opinion Holder and Target Detection: menentukan bagian yang merupakan opinion holder (pemberi opini) dan bagian yang merupakan target.

\subsection{Pembobotan TF-IDF}

Bobot TF-IDF merupakan bobot setiap kata pada setiap dokumen. Untuk memperoleh nilai TF - IDF menggunakan Persamaan 2. Untuk mendapatkan nilai TF IDF dibutuhkan nilai idf $f_{t}$ Nilai $i d f_{t}$ dapat dicari dengan Persamaan 1.

$$
\operatorname{idf}_{t}=\log _{10}\left(N / \mathrm{df}_{t}\right)
$$


Dimana $d f_{t}$ adalah jumlah dokumen yang mengandung suatu term dan $\mathrm{N}$ adalah total dokumen yang diuji.

$$
T F-I D F=t f x i d f_{t}
$$

idf adalah jumlah dokumen yang berisi istilah tersebut. Diambil log dari idf untuk memberikan beberapa penghalusan. Dalam hal ini, setiap dokumen dianggap sebagai vektor dengan 1 komponen yang sesuai dengan setiap term yang ada di kamus beserta dengan bobot dari setiap komponen. Untuk term yang tidak muncul di dokumen, maka bobotnya 0 .

Setelah didapatkan bobot TF-IDF pada setiap term, maka dilakukan normalisasi pada bobot TF-IDF tersebut. Normalisasi cosine dilakukan dengan perhitungan yang ditunjukkan pada Persamaan 3 (Croft, Metzler, \& Strohman, 2015).

$$
t f-i d f_{(\text {normalisasi })}=\frac{t f-i d f_{(a s l i)}}{\sqrt{\sum_{k=1}^{t}\left(t f-i d f_{(k)}\right)^{2}}}
$$

\subsection{Support Vector Machine}

SVM merupakan salah satu metode klasifikasi dengan menggunakan metode machine learning (supervised learning) yang memprediksi kelas berdasarkan pola dari hasil proses training yang diciptakan oleh Vladimir Vapnik. Klasifikasi dilakukan dengan garis pembatas (hyperlane) yang memisahkan antara kelas opini positif dan opini negatif. Secara intuitif, suatu garis pembatas yang baik adalah yang memiliki jarak terbesar ke titik data pelatihan terdekat dari setiap kelas, karena pada umumnya semakin besar margin, semakin rendah error generalisasi dari pemilah. Margin adalah jarak dari suatu titik vektor di suatu kelas terhadap hyperplane.

Berdasarkan Gambar 1, dapat dilihat bahwa garis pembatas terbaik adalah garis $\mathrm{H} 2$ karena memiliki maksimum margin dan membagi menjadi 2 kelas. Sedangkan H3 tidak membagi menjadi 2 kelas, dan H1 memang membagi menjadi 2 kelas, namun margin yang dimiliki sangat kecil. Hyperplane yang mewakili pemisahan atau margin terbesar antara dua kelas sehingga jarak titik data terdekat di setiap sisi dimaksimalkan disebut hyperplane margin maksimum, dan linier classifier yang didefinisikannya dikenal sebagai pengklasifikasi margin maksimal. Maksimum - margin hyperplane dan margin untuk SVM dilatih dengan sampel dari 2 kelas yang disebut support vector (Saraswati, 2011).

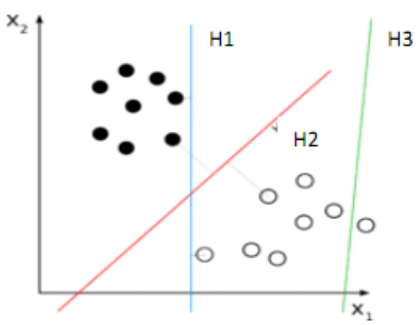

Gambarl. Contoh beberapa hyperlane

(Saraswati, 2011)

Training pada klasifikasi SVM akan menghasilkan sebuah nilai atau pola yang akan digunakan pada proses testing yang bertujuan untuk pemberian label sentimen (Novantirani, Sabariah, \& Effendy, n.d). Penilaian kemudian dibuat dengan menilai score yang merepresentasikan di sisi mana dokumen itu berada (Saraswati, 2011). Proses pengambilan keputusan dengan SVM beserta analisis berupa tingkat akurasi dan jumlah dokumen di setiap class positif, negatif, dan netral digambarkan seperti pada Gambar 2.

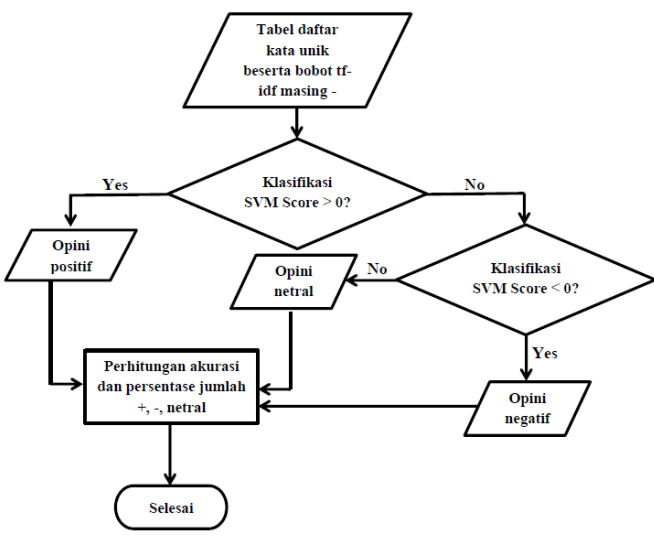

Gambar 2. Flowchart Klasifikasi dengan SVM dan Analisis

\subsection{Evaluasi dan Validasi}

Evaluasi performansi dilakukan untuk menguji hasil klasifikasi dengan mengukur nilai kebenaran dari sistem. Parameter yang digunakan untuk mengukur nilai kebenaran yaitu akurasi. Akurasi adalah persentase dokumen yang berhasil diklasifikasikan dengan tepat oleh sistem. Akurasi diperoleh dari hasil perhitungan yang ditunjukkan pada Persamaan 4.

$$
\mathrm{A}=\frac{T P+T N}{(T P+T N+F P+F N)}
$$

Semua parameter untuk mendapatkan akurasi didapatkan dari coincidence matrix yang digambarkan seperti Gambar 3. 


\begin{tabular}{|l|l|l|}
\hline & Relevant & Nonrelevant \\
\hline Retrieved & true positives (tp) & false positives (fp) \\
\hline Not retrieved & false negatives (fn) & true negatives (tn) \\
\hline
\end{tabular}

Gambar 3. Coincidence Matrix

(Manning, Raghavan, \& Schutze, 2009)

Proses validasi data latih berguna untuk meningkatkan nilai akurasi sistem. Proses validasi ini diharapkan akan menghasilkan batasan yang tepat untuk membagi tiga kelas sentiment secara adil dan memberikan pembobotan yang tepat sehingga akurasi dapat meningkat.

\subsection{Text Preprocessing}

Text preprocessing merupakan tahap awal dari text mining. Tujuan dari text preprocessing adalah untuk mempersiapkan dokumen teks yang tidak terstruktur menjadi data terstruktur yang siap digunakan untuk proses selanjutnya dengan cara menghilangkan noise, menyeragamkan bentuk kata dan mengurangi volume kata (Putranti \& Winarko, 2014). Tahapan text preprocessing yang digunakan pada penelitian ini antara lain tokenisasi, case folding, filtering, stopword removal.

Tokenisasi digunakan untuk mendapatkan semua term unik yang ada dalam sample data sekaligus berusaha mengubah data input yang tidak menggunakan bahasa baku (misalnya: singkatan dan bahasa asing yang sering muncul) menjadi bahasa Indonesia yang baku dan sesuai dengan KBBI dan EYD. Proses membakukan sebuah kata dilakukan dengan mendaftar kata - kata tersebut ke dalam sebuah tabel. Tabel ini memiliki field kata tidak baku dan kata baku. Contoh bentuk tabel disediakan pada Tabel 1 .

Tabel 1.

Tabel Kata Tidak Baku dan Kata Baku

\begin{tabular}{|c|c|}
\hline Kata Tidak Baku & Kata Baku \\
\hline Tdk & Tidak \\
\hline Enggak & Tidak \\
\hline Good & Baik \\
\hline Tlt & Terlambat \\
\hline Krg & Kurang \\
\hline
\end{tabular}

Case folding digunakan untuk mengubah semua karakter dokumen hasil tokenisasi menjadi lowercase agar dapat diurutkan secara alfabetik dan diproses selanjutnya.

Oleh karena sistem ini berpanduan klasifikasi adalah KBBI dan EYD, maka perlu adanya penyaringan agar yang diambil hanya term berbahasa Indonesia yang baku saja. Untuk kata yang disingkat namun sering muncul akan berusaha dibakukan. Sedangkan kata yang menggunakan bahasa asing, namun sering muncul, akan diterjemahkan ke dalam bahasa Indonesia. Tahap ini diharapkan dapat membuat kinerja sistem semakin akurat dan tepat sasaran.

Jumlah term yang terlalu banyak tidak efektif karena membutuhkan memory yang besar dan waktu pengerjaan yang cukup lama, sehingga perlu adanya pemilahan term. Term yang spesifik dan sesuai dengan topik dokumen (dalam hal ini kasus evaluasi dosen) dapat membantu kinerja sistem agar lebih efektif dan efisien.

\section{HASIL DAN PEMBAHASAN}

Pada pengujian pertama, Penulis menggunakan data latih sebanyak 307 dokumen. Dokumen latih terdiri dari 103 dokumen bersentimen positif, 163 bersentimen negatif, dan 41 dokumen bersentimen netral. Pada pengujian ini akan ditentukan range yang tepat untuk membagi menjadi 3 kelas sentimen. Melalui pengujian ini didapatkan akurasi tertinggi adalah 49,54\%. Akurasi ini didapatkan pada range :

\section{Positf: $>0 \quad$ Netral: $0 \quad$ Negatif: $<0$}

Untuk meningkatkan akurasi, Penulis mencoba untuk mengubah komposisi data latih dengan metode $k$-fold cross validation dengan $\mathrm{k}=7$. Melalui pengujian ini, didapatkan terjadinya perubahan tingkat akurasi yang cukup signifikan di beberapa dataset pelatihan. Hal ini membuktikan bahwa komposisi data latih turut mempengaruhi tingkat akurasi. Akurasi tertinggi didapatkan pada dataset dengan $\mathrm{k}=6$ dan akurasi yang dicapai adalah $67,83 \%$. Hasil pengujian ditunjukkan pada Tabel 2.

Tabel 2.

Tabel Hasil Pengujian Penerapan $K$-fold cross validation

\begin{tabular}{|c|c|c|c|c|c|c|c|c|c|c|c|}
\hline \multirow[b]{2}{*}{$\mathrm{K}$} & \multirow[b]{2}{*}{$\begin{array}{c}\text { Jumla } \\
\text { h } \\
\text { term } \\
\text { unik }\end{array}$} & \multicolumn{9}{|c|}{ Confusion Matriks } & \multirow[b]{2}{*}{$\begin{array}{c}\text { Akur } \\
\text { asi }\end{array}$} \\
\hline & & $\mathrm{P}, \mathrm{P}$ & $\begin{array}{l}\mathrm{P}, \\
\mathrm{N}\end{array}$ & $\begin{array}{l}\mathrm{P} \\
\text {, } \\
\mathrm{N} \\
\mathrm{t}\end{array}$ & $\begin{array}{l}\mathrm{N}, \\
\mathrm{P}\end{array}$ & $\begin{array}{l}\mathrm{N}, \\
\mathrm{N}\end{array}$ & $\begin{array}{l}\mathrm{N} \\
, \\
\mathrm{N} \\
\mathrm{t}\end{array}$ & $\begin{array}{l}\mathrm{Nt} \\
, \mathrm{P}\end{array}$ & $\begin{array}{c}\mathrm{Nt} \text {, } \\
\mathrm{N}\end{array}$ & $\begin{array}{l}\mathrm{Nt}, \\
\mathrm{Nt}\end{array}$ & \\
\hline 1 & 433 & 24 & 14 & 0 & 29 & 40 & 1 & 3 & 6 & 1 & 58,56 \\
\hline 2 & 416 & 24 & 13 & 3 & 21 & 45 & 1 & 3 & 6 & 3 & 65,45 \\
\hline 3 & 395 & 23 & 20 & 1 & 31 & 39 & 0 & 1 & 5 & 7 & 60,00 \\
\hline 4 & 402 & 23 & 18 & 3 & 21 & 45 & 3 & 4 & 4 & 4 & 61,54 \\
\hline 5 & 413 & 27 & 15 & 1 & 23 & 44 & 1 & 7 & 4 & 3 & 62,71 \\
\hline 6 & 413 & 34 & 6 & 1 & 23 & 43 & 2 & 6 & 8 & 1 & 67,83 \\
\hline 7 & 428 & 24 & 14 & 0 & 29 & 40 & 1 & 5 & 8 & 0 & 56,64 \\
\hline
\end{tabular}

Peningkatan akurasi berdasarkan jumlah term unik ditunjukkan pada Gambar 4. Melalui Gambar 4, dapat disimpulkan bahwa semakin banyak jumlah term unik, memiliki kecenderungan untuk meningkatkan akurasi. 


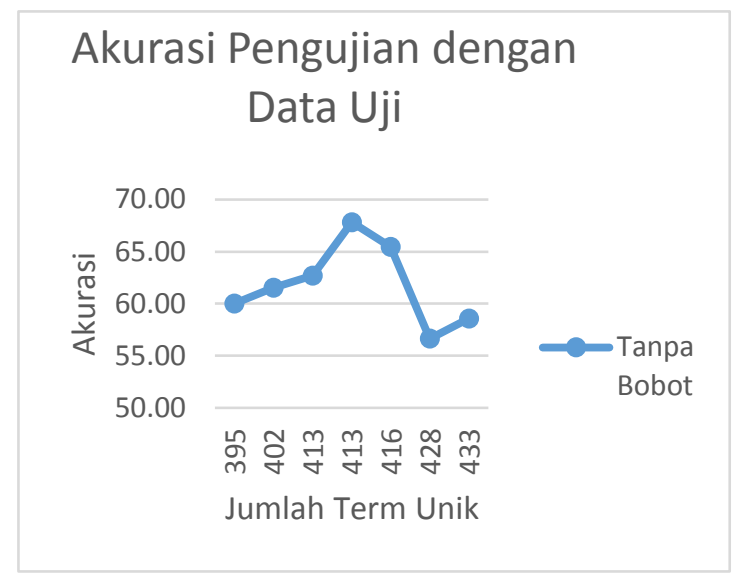

Gambar 4. Grafik Akurasi Hasil Pengujian

Sistem ini memiliki nilai akurasi yang tidak terlalu tinggi dikarenakan faktor dari dokumen uji yang dimasukkan. Bila dokumen uji yang dimasukkan semua term-nya adalah stopwords maka sistem tidak dapat melakukan sentiment analysis pada dokumen uji tersebut. Hal ini dikarenakan sistem menerapkan preprocessing stopwords removal yang artinya sistem akan membuang semua term yang tergolong stopwords. Akibatnya, dokumen uji tersebut dianggap tidak mengandung term apapun.

Faktor lain yang menghambat kinerja sistem adalah adanya dokumen uji yang semua term-nya tidak terdapat di dokumen latih, dengan kata lain sistem tidak pernah mengenal term ini sebelumnya. Apabila ada term baru dari dokumen uji, perhitungan tidak dapat dilanjutkan karena term tersebut tidak memiliki nilai untuk dimasukan ke persamaan hyperplane. Alasan inilah yang membuat dokumen uji bersentimen netral sulit terdeteksi sebagai kelas sentimen netral, karena pada umumnya kalimat bersentimen netral memiliki variasi term yang lebih beragam daripada kelas sentimen yang lain. Tidak seperti pada kelas sentimen positif dan negatif, kelas sentimen netral cenderung tidak memiliki term yang khas, sehingga sulit dikenali.

\section{KESIMPULAN DAN SARAN}

Berdasarkan hasil analisis penelitian, maka dapat ditarik kesimpulan bahwa sistem sudah dapat melakukan sentiment analysis dengan metode SVM terhadap hasil evaluasi dosen FTI UKDW Program Studi Teknik Informatika tahun ajaran 2014/2015 semester gasal. Dengan metode SVM, sistem dapat melakukan sentiment analysis dengan menggunakan 3 kelas sentimen. Akurasi tertinggi SVM pada sistem ini yaitu $67,83 \%$. Akurasi tertinggi dicapai pada sistem yang tidak menerapkan perubahan bobot pada dokumen uji dan menggunakan range $>0$ untuk kelas sentimen positif, $<0$ untuk kelas sentimen negatif, dan
0 untuk kelas sentimen netral, serta pelatihan menggunakan set datalatih ke 6.

Sistem pengklasifikasian ini sangat memungkinkan untuk dilakukan pengembangan lebih lanjut sesuai kebutuhan yang terus bertambah, sehingga dapat meningkatkan akurasi sistem. Saran yang diajukan Penulis dalam pengembangan sistem kedepannya adalah sebagai berikut:

1. Memperkaya variasi term untuk proses filtering yang mengatasi pembakuan kata dan menambah maupun mengurangi daftar stopword agar tidak terjadi terhapusnya kata yang merupakan ciri khas dari suatu class sentimen.

2. Menggunakan metode yang lebih baik untuk sistem penyelesaian persamaan linear agar terbentuk hyperplane yang lebih akurat. Akan lebih baik bila menggunakan algoritma yang dapat membentuk matriks inverse pada semua matriks (tidak hanya matriks persegi) agar sistem dapat mengatasi kasus jumlah dokumen latih lebih banyak dari jumlah term unik pada dokumen latih.

3. Pada penelitian ini, proses sentiment analysis dilakukan hanya berdasarkan pembobotan yang diukur dari angka kemunculan dan mengabaikan makna kata. Akan lebih baik bila pada penelitian selanjutnya diterapkan juga kedekatan suatu kata dengan kata yang lain (semantic). Misalnya mengkolaborasi tabel sinonim dengan tabel wordnet.

4. Berdasarkan hasil analisis, didapatkan hasil bahwa range pembatas antar kelas sentiment bisa saja berubah. Akan lebih baik bila sistem memiliki fitur yang memperbolehkan pengguna mengatur sendiri range tersebut.

\section{DAFTAR PUSTAKA}

[1] Croft, W. B., Metzler, D., \& Strohman, T. (2015). Search Engines Information Retrieval in Practice. Pearson Education, Inc.

[2] Feizar, F. H., Indrianti, \& Yudistira, N. (2014). Analisis Sentimen Opini Film Berbahasa Indonesia Berbasis Kamus Menggunakan Metode Neighbor-Weighted K-Nearest Neighbor. Universitas Brawijaya, Teknik Informatika. Malang: Universitas Brawijaya.

[3] Manning, C. D., Raghavan, P., \& Schutze, H. (2009). An Introduction to Information Retrieval. Cambridge, England: Cambridge University Press.

[4] Novantirani, A., Sabariah, M. K., \& Effendy, V. (n.d). Analisis Sentimen pada Twitter untuk Mengenai Penggunaan Transportasi Umum Darat Dalam Kota dengan Metode Support Vector Machine. Universitas Telkom, Teknik Informatika. Bandung: Universitas Telkom.

[5] Putranti, N. D., \& Winarko, E. (2014, January 15). Analisis Sentimen Twitter untuk Teks Berbahasa Indonesia dengan Maximum Entropy dan Support Vector Machine. IJCCS, 8, 91-100. 
[6] Saraswati, N. W. (2011). Text Mining dengan Metode Naive Bayes Classifier dan Support Vector Machines untuk Sentiment Analysis. Universitas UDAYANA, Teknik Elektro. Denpasar: Universitas UDAYANA.

[7] Wicaksono, A. F. (2011, Januari 20). My Live Journals. Dipetik September 15, 2015, dari Apa itu Sentiment Analysis / Opinion Mining?: http://alfanfarizki.blogspot.co.id/2011/01/apa-itu-sentiment-analysisopinion.html 